\title{
Gastric glomus tumor with prominent polytypic plasmacytosis: case report and review of literature
}

\author{
Ausra Garnelyte ${ }^{1}$, Narimantas E. Samalavicius ${ }^{2}$, Rokas Stulpinas ${ }^{1}$, Edita Baltruskeviciene ${ }^{2}$, \\ Dmitrij Seinin ${ }^{1}$, Ugnius Mickys ${ }^{1}$ \\ 1. National Center of Pathology, Affiliate of Vilnius University Hospital Santariskiu Clinics, Vilnius, Lithuania. 2. Institute of \\ Oncology, Vilnius University, Vilnius, Lithuania.
}

Correspondence: Rokas Stulpinas. Address: National Center of Pathology, P. Baublio 5, LT-08406 Vilnius, Lithuania. E-mail: rokas.stulpinas@gmail.com

Received: February 7, 2014

Accepted: April 9, 2014

Online Published: May 9, 2014

DOI : $10.5430 /$ crcp.v1n2p84

URL: http://dx.doi.org/10.5430/crcp.v1n2p84

\section{Abstract}

Glomus tumor is a rare benign mesenchymal tumor, mostly found in acral skin or superficial soft tissues, but it can occur in other locations. Glomus tumors in different locations share similar histological and immunohistochemical characteristics, although some aberrant features can be identified. We report a case of 41 year-old male with gastric glomus tumor, preoperatively diagnosed as CD117 negative gastrointestinal stromal tumor. Apart from the rare location, glomus tumor showed some other unusual features - peritumoral polytypic plasmacytosis and florid mesothelial hyperplasia. Although gastric glomus tumors are rare, they should be included in differential diagnosis of submucosal gastric tumors.

\section{Key words}

Glomus tumor, Stomach, Plasmacytosis, Mesothelial hyperplasia

\section{Introduction}

Glomus tumor (GT) is a benign mesenchymal neoplasm composed of cells resembling modified smooth muscle cells, found in normal glomus body. Glomus body is a specialized dermal structure responsible for thermoregulation. They are more numerous in acral skin, where most of the GT occur. However, some GT develop in locations, where glomus bodies are thought to be absent, suggesting that some GT may arise from perivascular smooth muscle cells, which can differentiate into glomoid cells ${ }^{[1]}$. GT are rare, comprising less than $2 \%$ of soft tissue tumors. They usually manifest as small benign subungual nodules, which are very painful when palpated or exposed to cold. Multiple GT account for about $10 \%$ of all GT and some of them are hereditary with autosomally dominant inheritance pattern ${ }^{[2]}$.

Malignant GT are exceptionally rare and represent only $1 \%$ of all GT ${ }^{[1]}$. They are more common in deep soft tissues rather than superficial soft tissues and internal organs.

\section{Case presentation}

A 41 year-old Caucasian male with tenderness in epigastric area was subjected to upper gastrointestinal endoscopy that revealed ulcerated tumor approximately $3 \mathrm{~cm}$ in diameter, located in the posterior wall of subcardiac region of the 
stomach, which was clinically thought to be lymphoma. An abdominal MRI scan confirmed irregular contrast-enhancing mass measuring $34 \mathrm{~mm} \times 35 \mathrm{~mm}$ and located in gastric fundus between the posterior gastric wall, spleen and crus of diaphragm (see Figure 1).

Figure 1. MRI scan showing irregular contrast-enhancing mass, located in gastric fundus between the posterior gastric wall, spleen and crus of diaphragm.

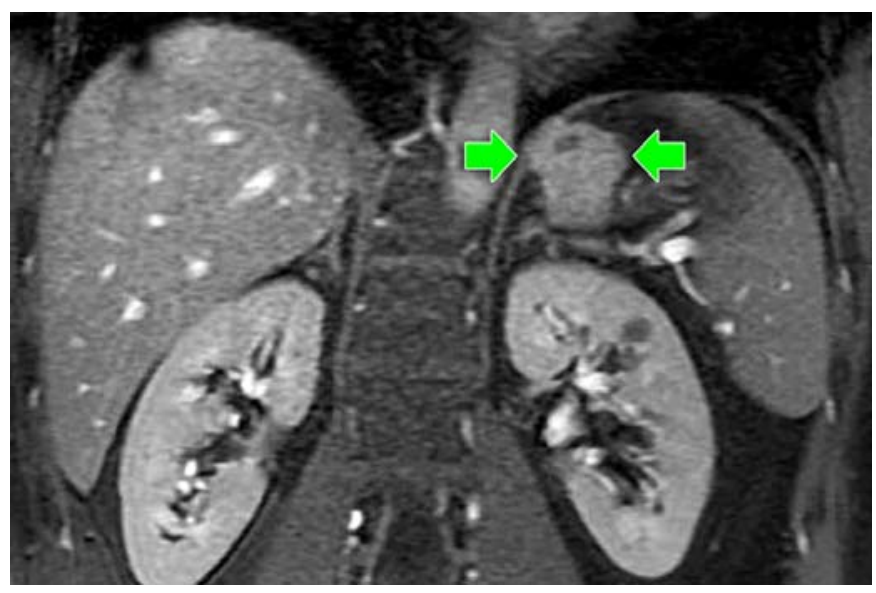

No metastases were found. Histological examination of endoscopic biopsy revealed a tumor composed of small round and spindle cells with eosinophilic cytoplasm. Tumor cells were negative for CD117 and suggested a diagnosis of a CD117 negative gastrointestinal stromal tumor (GIST). Patient underwent resection of gastric fundus and had an uneventful recovery. At four months of follow up MRI and endoscopy showed no evidence of recurrent tumor.

\section{Gross and histological features}

Fragment of gastric wall measuring $3.7 \mathrm{~cm} \times 3.6 \mathrm{~cm} \times 0.7 \mathrm{~cm}$ was sent for pathological examination. Grossly, the specimen contained submucosal nodule $3.2 \mathrm{~cm} \times 2.5 \mathrm{~cm} \times 3.3 \mathrm{~cm}$ in size. The cut surface of the nodule contained bright brown myxoid tumor spreading into subserosa. Microscopically, tumor was slightly nodular with collagenous septation, massive peritumoral and intratumoral plasmacytosis and peritumoral lymphoid follicles. Tumor was formed of small to medium sized epithelioid, focally spindle cells with eosinophilic or clear cytoplasm with focally prominent cytoplasmic borders and ovoid monomorphic nuclei with low mitotic activity (1 mitosis / 50 HPF) (see Figure 2).

Figure 2. Glomus tumor with prominent peritumoral and intratumoral plasma cell infiltrate $(H \& E, \times 200)$.

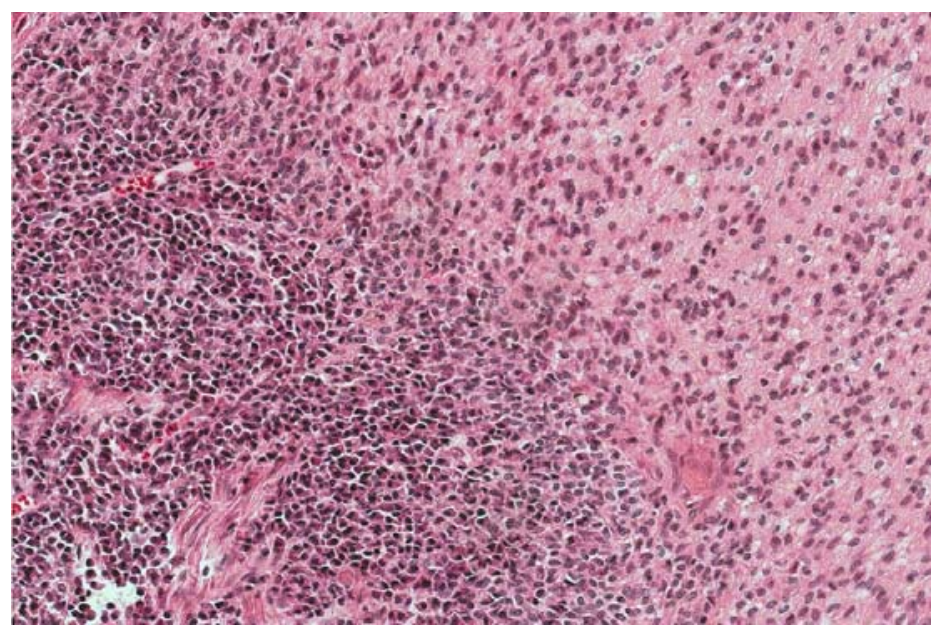

Slightly edemic/myxoid areas, hemorrhages with siderophages and several calcifications were observed in the tumor. No necrosis or vascular involvement was detected. Gastric mucosa above the tumor was hyperplastic with immature intestinal metaplasia and abundant lymphoid follicles. Surgical margins were free of tumor and single lymph node was free of metastatic cells. Immunohistochemically, tumor cells were positive for Smooth muscle actin (SMA), Vimentin, Collagen type IV, Epithelial membrane antigen (EMA), CD10, CD57, Progesterone receptors (PR), with weak focal positivity for 
CD34 and negative for CD117 (with a few positive mastocytes), DOG1, Desmin, Calretinin, Heavy Caldesmon, Synaptophysin, Chromogranin A, Laminin, S100, CD20, HMB45 and Melan A (see Figure 3). Ki67 proliferative activity was less than $2 \%$.

Figure 3. Immunohistochemical features in glomus tumor. A. Smooth muscle actin (SMA) is expressed in $60 \%$ of glomus tumor cells. B. All tumor cells are negative for CD117 with a few positive mastocytes. C. All tumor cells are negative for Desmin. D. All tumor cells are negative for Chromogranin A.

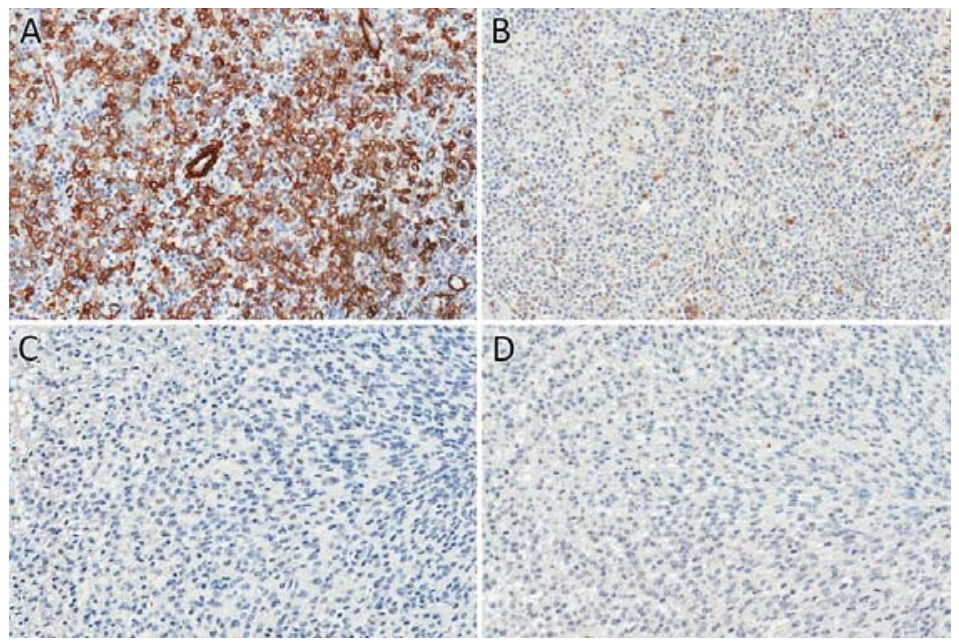

Mutation analysis of the tumor revealed wild-type sequences of exons 9, 11, 13 and 17 of C-KIT gene, exons 12, 14 and 18 of PDGFRA gene and exon 15 of BRAF gene by Sanger Sequencing using ABI 3500 platform.

Prominent tubulo-cystic and papillary mesothelial structures with flattened, cuboidal or columnar vacuolated cells, lymphoid infiltration and subepithelial lymphoid follicles were abundant in the serosa above the tumor (see Figure 4).

Figure 4. Prominent mesothelial hyperplasia in the serosa. $(\mathrm{H} \& \mathrm{E}, \times 100)$

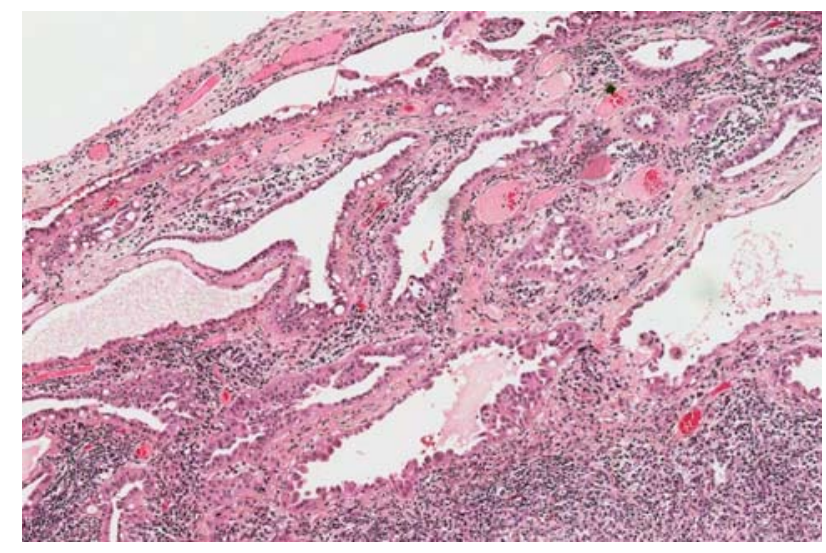

Mesothelial cells were slightly polymorphic with inconspicious nucleoli and without mitotic activity. Hyperplastic mesothelium showed slightly aberrant immunophenotype and was positive for Pancytokeratin (PanCK), CK5, EMA, WT1, Ber-EP4, ER and PR, with weak focal positivity for Calretinin and negative for Desmin. Tumor was infiltrated with abundant CD138 and IgG positive plasmacytes, with a few scattered IgG4 positive cells. Plasma cell population showed no kappa or lambda light chain restriction, suggesting polytypic plasmacytosis. Polyclonality was confirmed by additional molecular studies for immunoglobulin heavy (IgH) and kappa (IgK) chains using BIOMED-2 primer system in a capillary electrophoresis format (ABI 3500). Histologic features, immunophenotype and molecular genetic analysis supported the diagnosis of primary gastric glomus tumor with massive polytypic plasmacytosis and florid mesothelial hyperplasia.

\section{Discussion}

Majority of glomus tumors occur as small sporadic neoplasms in distal extremities, mostly in subungual region ${ }^{[2]}$. GT in visceral locations are very rare and mostly found in gastrointestinal tract, especially gastric antrum ${ }^{[3,4]}$ and duodenum, 
although tumors in colon ${ }^{[5]}$, trachea ${ }^{[6]}$, bronchus ${ }^{[7]}$, lungs ${ }^{[8,9]}$, kidney ${ }^{[10,11]}$, urinary bladder ${ }^{[12]}$, ovaries ${ }^{[13]}$, liver ${ }^{[14,15]}$, breast ${ }^{[16]}$, bone ${ }^{[17]}$, skeletal muscle ${ }^{[18]}$ and other organs were described. The incidence of gastric GT is $1 \%$ of GISTs ${ }^{[5]}$. Gastric GT usually occur in the fifth or sixth decade of life with a significant female predominance ${ }^{[4,5]}$, although some publications show equal or even male predominance ${ }^{[19]}$. Gastric GT manifest as small circumscribed intramural masses measured from $1.3 \mathrm{~cm}$ to $7.0 \mathrm{~cm}$ (median $2.5 \mathrm{~cm}$ ) ${ }^{[5]}$. These tumors often cause acute or chronic gastrointestinal bleeding or ulcer-like symptoms, but sometimes they can be an incidental finding during endoscopy or surgery. GT are composed of glomus cells, vascular structures and smooth muscle and, according to predominant component, are subcategorized as solid glomus tumor, glomangioma and glomangiomioma. Gastric GT histologically and immunohistochemically is similar to peripheral GT and consists of sheets of round epithelioid cells with sharp cell borders, amphophilic to lightly eosinophilic cytoplasm with small uniform nuclei with low mitotic activity. Tumor cells both in peripheral and gastric GT are positive for SMA, Vimentin, Calponin, Heavy Caldesmon, Collagen type IV, Laminin and negative for CD117, Desmin, Chromogranin, S100 and keratins. Some gastric GT show positivity for Synaptophysin, which is uncommon for peripheral GT ${ }^{[5]}$. GT show wild-type sequences of C-KIT gene, which helps to differentiate them from GIST. In one publication authors reported that $10 \%$ of sporadic glomus tumors had BRAF V600E mutation and 3\% had KRAS G12A mutation, although none of the mutated GT were located in the stomach ${ }^{[20]}$. Usually GT are benign, but occasionally they show atypical features and metastasize. Metastatic risk is increased for tumors in deep location, size larger than 2.0 $\mathrm{cm}$ and the presence of atypical mitotic figures. According to these features, atypical glomus tumors were classified into four groups: malignant GT, symplastic GT, glomus tumor of uncertain malignant potential and glomangiomatosis ${ }^{\text {[21] }}$.

\section{Differential diagnosis}

Subepithelial gastric GT should be differentiated from GIST, leiomyoma, neuroendocrine tumors, paraganglioma, perivascular epithelioid cell tumors (PEC’omas), schwannoma and lymphoma. Solid areas of tumor cells with cystic and papillary structures gave impression of ectopic extrapancreatic solid and pseudopapillary tumor. Although CD10, Vimentin and PR were positive, Synaptophysin was negative, which ruled out this diagnosis. Due to mesenchymal and epithelial components, another differential diagnosis was benign biphasic tumor (gastroblastoma). This diagnosis was excluded because mesenchymal component was positive for SMA and epithelial structures were negative for c-KIT and positive for Calretinin.

Gastric GT can show histological similarity to GISTs, especially epithelioid type, which was the first differential diagnostic issue in our case. GIST is usually positive for CD117 (and DOG1 in case of CD117 negative GIST), which is the key feature, and often for CD34, while GT is always negative for CD117 and DOG1 and rarely shows focal positivity for CD34 ${ }^{[5]}$. Similar histological features can be observed in GT and epithelioid leiomyoma and although both are positive for SMA, GT is always negative for Desmin. Neuroendocrine markers Synaptophysin and Chromogranin A can be used in differentiation between GT and gastric neuroendocrine tumors or paraganglioma - the latter two being positive for neuroendocrine markers and paraganglioma being also positive for S100, while GT is negative for all of them, except the rare cases of GT showing positivity for Synaptophysin ${ }^{[5]}$. S100 also helps differentiating GT from schwannoma, which is always positive. Melanocytic markers HMB45 and Melan A are helpful in differential diagnosis of GT versus perivascular epithelioid cell tumors (PEC'omas), whereas PEC'omas are positive and GT negative. Some of lymphomas, composed of small round cells, may histologically resemble GT, but these tumors can be easily distinguished with the help of lymphocytic markers, such as CD20 or CD45.

Our case had a few distinctive features that had never been described in literature before.

Peritumoral plasmacytosis was an unusual finding and was differentiated between reactive and neoplastic processes. Monoclonal plasmacytosis in GT would have led to diagnosis of collision tumor, but immunohistochemical and molecular studies revealed polyclonal nature of plasma cells, so plasmacytosis was considered to be reactive process. West and Buckley (1992) described a case of gastric GT, infiltrated by mantle cell lymphoma ${ }^{[22]}$. Another case of retroperitoneal schwannoma with monoclonal plasma cell infiltration was reported ${ }^{[23]}$, but there are no case reports on gastric GT with 
neither monoclonal nor polyclonal plasmacytosis. One case of intramuscular GT with a prominent mastocytic component was reported, with authors suggesting that mastocytes could have an important role in the mediation of pain ${ }^{[18]}$.

Tubulo-cystic and papillary structures in the serosa above the tumor was differentiated between hyperplastic mesothelium and duplication cysts or ectopic pancreatic ducts, but strictly subserosal location and immunophenotype of these structures suggested mesothelial origin. Hyperplastic mesothelium was also differentiated between reactive and neoplastic, however aberrant immunophenotype (CK5+, EMA+, WT1+, Ber-EP4+, ER/PR+, Calretinin+, Desmin-) is not common to neither reactive nor neoplastic mesothelium. Desmin, EMA, p53, GLUT-1 and IMP3 are reported to be most helpful in differentiation between benign reactive and neoplastic mesothelial proliferations ${ }^{\text {[24] }}$. EMA, p53, GLUT-1 and IMP3 are claimed to be markers of malignancy and Desmin is usually expressed in benign mesothelium. According to different publications, the role of immunohistochemistry in separating benign and malignant mesothelial proliferations is controversial. Churg and Galateau-Salle (2012) reported that Desmin, EMA and p53 are not beneficial in separation between benign and neoplastic mesothelial proliferations in individual cases ${ }^{[25]}$. Ber-EP4 is usually negative in both benign and malignant mesothelium and positivity suggests other than mesothelial origin, although positivity for Calretinin (even focal) proved mesothelial origin of tubulo-cystic and papillary structures in the serosa. Immunohistochemistry is more valuable to demonstrate invasion of the mesothelial cells into underlying tissues or to differentiate malignant mesothelioma from other tumors, rather than differentiating between benign reactive and neoplastic mesothelial proliferations ${ }^{[26]}$. Histological features are more helpful than immunohistochemistry. Absence of stroma invasion, simple papillae, single cell layers, loose sheets of cells without stroma, no necrosis, inflammatory infiltrate and uniformity of growth are the features in favor of reactive mesothelial hyperplasia ${ }^{[24]}$.

The significance of prominent reactive polytypic plasmacytosis and perineoplastic mesothelial hyperplasia with aberrant immunophenotype still remains unclear.

In summary, gastric glomus tumors are benign, rarely metastasize and show good prognosis. Surgical resection of the tumor is the best option of treatment. Recurrence of tumor is rare and associated with non-radical resection ${ }^{[18]}$. Due to rarity, nonspecific immunophenotype and, as in our case, peritumoral epiphenomena (plasmacytosis/mesothelial hyperplasia) some differential diagnosis problems may evolve and pathologists must be aware of it.

\section{Acknowledgement}

We thank prof. K. D. Kunze for review of the case on INCTR iPath telepathology platform.

\section{References}

[1] Gombos Z, Zhang PJ. Glomus tumor. Arch Pathol Lab Med. 2008; 132: 1448-52. PMid: 18788860.

[2] Fletcher CDM UK, Meretens F, editors. Pathology and Genetics of Tumours of Soft Tissue and Bone, in, World Health Organization Classification of Tumours, IARC, Lyon, France. 2002; 136-37.

[3] Kapur U, Hobbs CM, McDermott E, Mooney EE. Gastric glomus tumor. Ann Diagn Pathol. 2004; 8: 32-5. PMid: 15129908. http://dx.doi.org/10.1016/j.anndiagpath.2003.11.008

[4] Lee HW, Lee JJ, Yang DH, Lee BH. A clinicopathologic study of glomus tumor of the stomach. J Clin Gastroenterol. 2006; 40: 717-20. PMid: 16940885. http://dx.doi.org/10.1097/00004836-200609000-00011

[5] Miettinen M, Paal E, Lasota J, Sobin LH. Gastrointestinal glomus tumors: a clinicopathologic, immunohistochemical, and molecular genetic study of 32 cases. Am J Surg Pathol. 2002; 26: 301-11. PMid: 11859201. http://dx.doi.org/10.1097/00000478-200203000-00003

[6] Okereke IC, Sheski FD, Cummings OW. Glomus tumor of the trachea. J Thorac Oncol. 2011; 6: 1290-1. PMid: 21847042. http://dx.doi.org/10.1097/JTO.0b013e31821f967d

[7] Zhu YZ, Li WP, Wang ZY, Yang HF, He QL, Zhu HG, et al. Glomus tumor of uncertain malignant potential arising in the bronchus. Journal of cardiothoracic surgery. 2013; 8: 146. PMid: 23758949. http://dx.doi.org/10.1186/1749-8090-8-146 
[8] De Cocker J, Messaoudi N, Waelput W, Van Schil PE. Intrapulmonary glomus tumor in a young woman. Interact Cardiovasc Thorac Surg. 2008; 7: 1191-3. PMid: 18682431. http://dx.doi.org/10.1510/icvts.2007.172957

[9] Dalfior D, Parisi A, Cannizzaro C, Bontempini L, Di Pace C, Menestrina F, et al. Pulmonary glomus tumor. Int J Surg Pathol. 2008; 16: 81-4. PMid: 18203793. http://dx.doi.org/10.1177/1066896907304520

[10] Sugimoto K, Yamamoto Y, Hashimoto K, Esa A, Okamoto S. Glomus tumor of the kidney. Int J Urol. 2010; 17: 187-8. PMid: 20377837. http://dx.doi.org/10.1111/j.1442-2042.2009.02433.x

[11] Sasaki K, Bastacky SI, Hrebinko RL, Parwani AV, Zynger DL. Glomus tumor of the kidney: case report and literature review. Int J Surg Pathol. 2011; 19: 393-7. PMid: 19164408. http://dx.doi.org/10.1177/1066896908331233

[12] Tripodi SA, Rocca BJ, Mourmouras V, Barbanti G, Colecchia M, Ambrosio MR. Benign glomus tumor of the urinary bladder. Arch Pathol Lab Med. 2013; 137: 1005-8. PMid: 23808474. http://dx.doi.org/10.5858/arpa.2012-0125-CR

[13] Maeda D, Takazawa Y, Oda K, Nakagawa S, Fukayama M. Glomus tumor of the ovary: a case report. Int J Surg Pathol. 2010; 18: 557-60. PMid: 20667926.

[14] Geramizadeh B, Nikeghbalian S, Shamsaifar A, Kazemi K, Tavoosi H, Sefidbakht S, et al. Primary glomus tumor of the liver: a rare case report and review of the literature. Indian J Pathol Microbiol. 2011; 54: 584-7. PMid: 21934228. http://dx.doi.org/10.4103/0377-4929.85101

[15] Amoueian S, Meibodi NT, Tavoosi H, Ekramifard VR, Attaranzadeh A, Montazer M. Primary glomus tumor of the liver. Archives of Iranian medicine. 2011; 14: 294-5. PMid: 21726110.

[16] Yalcin S, Ergul E, Ucar AE, Ulger BV, Korukluoglu B. Glomus tumor of the breast: first report. Langenbeck's archives of surgery / Deutsche Gesellschaft fur Chirurgie. 2009; 394: 399-400. PMid: 18446361. http://dx.doi.org/10.1007/s00423-008-0337-z

[17] Le Corroller T, Hargunani R, Khashoggi K, Hayes MM, Clarkson PW, Ouellette HA, et al. Primary intraosseous glomus tumor in a middle phalanx. Skeletal Radiol. 2012; 41: 227-30. PMid: 21656134. http://dx.doi.org/10.1007/s00256-011-1217-0

[18] Rodriguez JM, Idoate MA, Pardo-Mindan FJ. The role of mast cells in glomus tumours: report of a case of an intramuscular glomus tumour with a prominent mastocytic component. Histopathology. 2003; 42: 307-8. PMid: 12605654. http://dx.doi.org/10.1046/j.1365-2559.2003.15355.x

[19] Kang G, Park HJ, Kim JY, Choi D, Min BH, Lee JH, et al. Glomus tumor of the stomach: a clinicopathologic analysis of 10 cases and review of the literature. Gut and liver. 2012; 6: 52-7. PMid: 22375171. http://dx.doi.org/10.5009/gnl.2012.6.1.52

[20] Chakrapani A, Warrick A, Nelson D, Beadling C, Corless CL. BRAF and KRAS mutations in sporadic glomus tumors. Am J Dermatopathol. 2012; 34(5): 533-5. PMid: 22317887. http://dx.doi.org/10.1097/DAD.0b013e31823931b4

[21] Folpe AL, Fanburg-Smith JC, Miettinen M, Weiss SW. Atypical and malignant glomus tumors: analysis of 52 cases, with a proposal for the reclassification of glomus tumors. Am J Surg Pathol. 2001; 25: 1-12. PMid: 11145243. http://dx.doi.org/10.1097/00000478-200101000-00001

[22] West AB, Buckley PJ. Mantle zone lymphoma in a gastric glomus tumor. Cancer. 1992; 70: 2246-9. http://dx.doi.org/10.1002/1097-0142(19921101)70:9<2246::AID-CNCR2820700905>3.0.CO;2-R

[23] Damasena I, Low I, Carey-Smith R. Retroperitoneal schwannoma with monoclonal plasma cell infiltration: an exceptionally rare collision tumor? Int J Surg Pathol. 2013; 21: 635-8. PMid: 23248338. http://dx.doi.org/10.1177/1066896912468612

[24] Husain AN, Colby T, Ordonez N, Krausz T, Attanoos R, Beasley MB, et al. Guidelines for pathologic diagnosis of malignant mesothelioma: 2012 update of the consensus statement from the International Mesothelioma Interest Group. Arch Pathol Lab Med. 2013; 137: 647-67. PMid: 22929121. http://dx.doi.org/10.5858/arpa.2012-0214-OA

[25] Churg A, Galateau-Salle F. The separation of benign and malignant mesothelial proliferations. Arch Pathol Lab Med. 2012; 136: 1217-26. PMid: 23020727. http://dx.doi.org/10.5858/arpa.2012-0112-RA

[26] Cagle PT, Churg A. Differential diagnosis of benign and malignant mesothelial proliferations on pleural biopsies. Arch Pathol Lab Med. 2005; 129: 1421-7. PMid: 16253023. 